\title{
Predicting Citizens Acceptance of Government-led e-Participation Initiatives through Social Media: A Theoretical Model
}

\author{
Ayman Alarabiat \\ Department of Information Systems \\ Centro ALGORITMI \\ University of Minho, Portugal \\ aymanalarabiyat@gmail.com
}

\author{
Delfina Sá Soares \\ Department of Information Systems \\ Centro ALGORITMI \\ University of Minho, Portugal \\ dss@dsi.uminho.pt
}

\author{
Elsa Estevez \\ Department of Computer Science and \\ Engineering \\ Universidad Nacional del Sur, Argentina \\ ecestevez@gmail.com
}

\begin{abstract}
Whilst the idea of utilizing social media to advance government-led e-Participation initiatives has proliferated significantly in recent years, mostly such initiatives do not meet the intended expectations, as the majority of them fail to attract wider citizens' audience. Overall, the key factors that could explain and predict citizens' participation are not yet thoroughly identified. Therefore, the current study develops a theoretical citizen-centric model that seeks to explain and predict the intention of citizens' behavior towards their involvement in government-led e-Participation initiatives through social media. The methodological approach is primarily based on utilizing and extending one of the well-known theories for describing a person acceptance behavior, namely the Theory of Planned Behavior. The model applies the main constructs of the Theory - attitude, subjective norms, and perceived behavioral control; and complements them with several constructs drawn from relevant literature. The paper contributes to understanding the reasons why citizens decide to engage or not in government-led e-Participation initiatives through social media.
\end{abstract}

\section{Introduction}

The concept of e-Participation has introduced a new perspective on the usage of digital technologies in the public sector, which primarily seeks to reinforce citizens interaction with policy makers (governments and politicians) and to enhance citizens participation in policy- and government- decision making processes [36,55]. Paradoxically, the main problem to solve in e-Participation initiatives is the actual participation of citizens [37,55], since a low level of citizens acceptance and engagement is often recognized in the majority of e-Participation initiatives [35,37,55,57]. Likely, the problem arise due to a misplaced focus of many e-Participation projects, meaning that their major concern is on delivering technological solutions rather than on understanding citizens' needs [61].

The trend of citizens to use social media to express their opinions is encouraging more governments to follow citizens on those networks rather than expecting them to come to governments websites $[14,44]$. Therefore, many government-led eParticipation initiatives have been linked to several social media networks - in particular, Facebook and Twitter - in an effort to enhance citizens engagement $[10,30,41,45]$. Despite such efforts, the challenge of e-Participation initiatives to engage more citizens still remains [14,48,57].

Understanding why citizens are not willing to engage with government issues, and investigating citizens' acceptance and intention to participate is an essential step to analyze actual levels of citizens' participation. On the one side, too often it is assumed that such initiatives begin and end basically with the provision of social media profiles for disseminating information, with limited government commitment and weak strategies to foster dialogues with citizens over these networks $[10,38]$. On the other side, there is a trend to believe that citizens will get involved without due consideration of their preferences, needs and expectations $[43,44,57]$. This is probably due to one major deceptive notion that citizens will and/or want to participate immediately when they are just given e-Participation tools [24,55,57]. In this respect, the Organization for Economic Co-operation \& Development explains that not all citizens are willing to participate, and certain citizens segments are able but unwilling to participate [44]. Consequently, even the usage of social media is expected to bring e-Participation to a new stage [3,14,23,30,38,56], a low level of success has been reached and citizens involvement is still limited $[10,30,41,43]$.

Based on the identified problem, our research objective is to derive an analytical model in which citizens' perception and attention towards the usage of government-led e-Participation initiatives through 
social media can be understood, explained, and predicted. This paper introduces a model to achieve such objective. Specifically, the work presented in this paper addresses the following research question: what are the relevant factors to influence citizens' intention to accept and to engage in government-led e-Participation through social media initiatives?

We believe that e-Participation through social media promises indeed new opportunities for government to strengthen the relationship with citizens and to enhance their engagement in formulating government decisions, but the desirable participation level is mainly and firstly conditioned by citizen acceptance of such participation. Considering this, an analysis of citizens' personal perception and acceptance could be one pathway to clarify the low level of citizens participation $[24,30]$. Accordingly, and since e-Participation initiatives are concerned with individuals, our framework is based on the foundational psychological idea that "beliefs" formulate "attitudes", which in turn affect "intentions" that subsequently drive "behaviors" [1]. Such idea is well-examined and explained in the Theory of Planned Behavior (TPB) [1]. The TPB shows a high capacity for explaining and predicting an individual acceptance behavior in various contexts $[5,16,33,47,62]$. Briefly, this theory seeks to understand and predict why a person may perform (or not perform) certain behaviors [1]. It states that a person's actual behavior can be predicted by his/her intention to perform that behavior. Simultaneously, behavior intention is preceded by three constructs: person's attitude, subjective norms, and perceived behavior control [1].

The TPB serves as the theoretical foundation for this study since it deals with the complexities of human social behavior through seizing social and behavioral factors [62]. In addition, it has been found effective particularly in the areas of voluntary usage, e.g. social media users behavior $[5,15]$. Interestingly, e-Participation is also, by nature, a voluntary activity of citizens who can freely decide to participate or not $[17,24,36,55]$. The suitability of TPB for the current study is further discussed in Section 4.

The remainder of this paper is organized as follows. Section 2 presents the rationality behind the current study. Section 3 discusses some key findings of related work on limited citizens' participation. Following, Section 4 describes the theoretical basis for this work; while Section 5 presents and validates the proposed model. Finally, Section 6 concludes the paper and outlines some future work.

\section{Research rationality and contribution}

It could be argued that previous literature seems to be underestimating the complexity of the environment that surrounds citizens participation initiatives, which is turbulent, confused, and comprise various political, social, behavioral, cultural, and technological dimensions [24,35,56], particularly when those initiatives are implemented through social media $[23,56]$. The latest reviews of eParticipation literature suggests an ongoing shift of the research from a more purely technological focus to a more holistic view, where other social and technological issues could be integrated to investigate citizens' engagement [37,60]. In fact, so far, identifying and investigating those dimensions have attracted limited researchers attentions [37,60]. In this sense, approaching the phenomenon of citizens' involvement in e-Participation through social media initiatives in a multi-disciplinary way, as is done in this study, seems to be a rational decision. Pioneer scholars stress the necessity of a multi-disciplinary approach, in which e-Participation domain can greatly benefit from other disciplines [35,36,60]. However, few researchers have adopted multiple perspectives when studying e-Participation topics. This led to the increase of the internal disciplinary boundaries that currently characterize e-Participation research [60].

The current study aims at developing a model for citizens' intention and not citizen's actual involvement into e-Participation through social media initiatives. The arguments follow. First, using social media in e-Participation is still an emerging phenomenon, particularly in government context [66], and in many countries such initiatives are only in an infancy stage [14], what means that citizens may have little or no awareness that such initiatives exist. Second, considering mandatory versus voluntary contexts, the intention to use may be a more appropriate dependent variable in volunteered usage environments [11,22]. Third, the concepts of acceptance and adoption have been usually used interchangeably particularly in e-Government studies $[35,57]$. Nevertheless, in the area of information systems (IS) those concepts are distinct. According to [64], the adoption comes after direct experience with the technology and after an individual (potential user) has decided to accept using this technology. Fourth, based on measuring citizens' intention, as provided by TPB, we can predict the potential of citizens engagement when e-Participation initiatives become available or when citizens become aware of them [40].

The current study is one of the first studies that addresses the issue of citizens' perception of 
e-Participation in it is own right and abreast with social media. Additionally, there are few examples of studies focused on government-led e-Participation initiatives specifically through social media [66], and little attention has been given towards understanding citizens' perspectives and needs in this kind of initiatives $[37,60]$.

Further insight into e-Participation through social media in e-Government context reveals that the majority of them are giving more consideration to the analysis of issues on the government side (e.g. $[25,30,38,45])$ rather than to the perceptions on the recipients side - a perspective deserving further research [14,30,57].

Thus, we argue that this study contributes to the theoretical growth of e-Participation literature. The proposed model will be helpful for discovering whether citizens accept to engage in e-Participation through social media initiatives, being a sound starting base on which to build a more comprehensive view of citizens' acceptance and adoption in the context of e-Participation. The model also helps academics to address citizen needs in order to conduct further studies on how to lower barriers that may prevent greater citizen participation $[30,35,36,44]$.

\section{Related work}

This section focusses on related work studying the particular issue of limited citizens' participation and relevant factors that may influence citizens' attention to accept and to engage in e-Participation initiatives.

Several previous studies demonstrate that the success of e-Participation could not be attained only through providing technical tools $[57,61]$, and that the solely availability of various e-Participation tools does not necessarily guarantees citizens' interest and engagement in such initiatives [35,36,42,55,61]. In this sense, more concern should be put around what is beyond the development and offering of eParticipation tools [42]. Probably, there are other determinant factors that influence citizens' participation [24,35]. In fact, e-Participation is far more than simply introducing new technologies $[36,42,55]$, and citizens' personal and social acceptance to be involved in e-Participation activities appear as crucial factors $[19,24,36,42]$. There is some evidence that the availability of sophisticated e-Participation tools, which demands high technical skills from citizens significantly reduces citizens ability and willingness to participate [34,37,51,61]. Another evidence is that the use of weak communication means to reach and to interact with citizens in e-Participation projects also reduces citizens ability and willingness to participate [34,51]. However, technological factors were not the only barriers; since other non-technical factors - e.g. social, political, behavior, and cultural; may have a significant impact on citizens' engagement [4,24, 27,36]. For instance, citizens' political efficacy, freedom to participate [4], and citizens' awareness and interest in policy issues [27] have a significant effect on citizen participation. Some authors highlight the role of citizens' ability, attitudes and social acceptability determinants as influencers of their decision to participate $[20,36,60]$. Others, stress the role of citizens trust in government as an influence factor for adopting and actively be involved in government e-Participation initiatives [27,57,58].

Another important factor that may cause limited citizens engagement is the lack of commitment exhibited by many government officials to open truly deliberation to citizens $[9,35,49,57]$. In fact, many citizens' opinions, views, and feedback are been rarely considered in final government decisions $[39,65]$. Lack of government commitments raises citizen's suspicious that e-Participation initiatives might lead to nothing [49]. Rationally, citizens perceive that the benefits of their interaction with government through e-Participation initiatives are positively associated with the acceptance of such interaction. Thus, citizens may decide to get involved in e-Participation based on whether or not they believe their input has any influence on government policies and decisions [35,36,37,39,65].

A closer look in social media for e-Participation literature reveals that while several studies have examined the use of social media in the government context, they have not investigated their use specifically for e-Participation purposes $[3,23,25$, 30,45]. Despite the fact that social media is changing general expectations surrounding the interactions with government, previous research works focus on the influence of using social media on government openness, transparency, and improved service delivery but not on e-Participation [10,41]. Those studies conclude that the majority of government initiatives largely prioritize the dissemination of information over reciprocal discussions with citizens through social media platforms - very few initiatives use such platforms for interacting with citizens. For example, the use of social media in 75 largest USA cities between 2009 and 2011 were more concerned with dissemination of information rather than with inviting citizens to participate [41]. Similar results were also found in European cities [10]. Generally, the majority of research on e-Participation through social media have devoted great focus on government institutions perspective $[10,39,41,45]$. Some studies 
follow in depth case studies [41], content analysis [10] and few have applied theoretical approach such as [45].

\section{Theoretical framework}

Researchers have been using several theories and models to explain and predict users' acceptance and adoption of new technologies and systems, particularly in e-Government and IS fields [31,52].

As shown in Figure 1, TPB is a social-psychological theory that attempts to predict and understand why a person may perform certain behaviors [1]. The theory suggests that a person's intention to perform a behavior (BI) can be a strong predictor of his/her actual behavior (AB). BI can be understood as the degree that a person is willing to try or perform a certain behavior, and is determined by three conceptually independent determinants: Attitude towards Act or Behavior (ATT), Subjective Norms (SN), Perceived Behavioral Control (PBC).

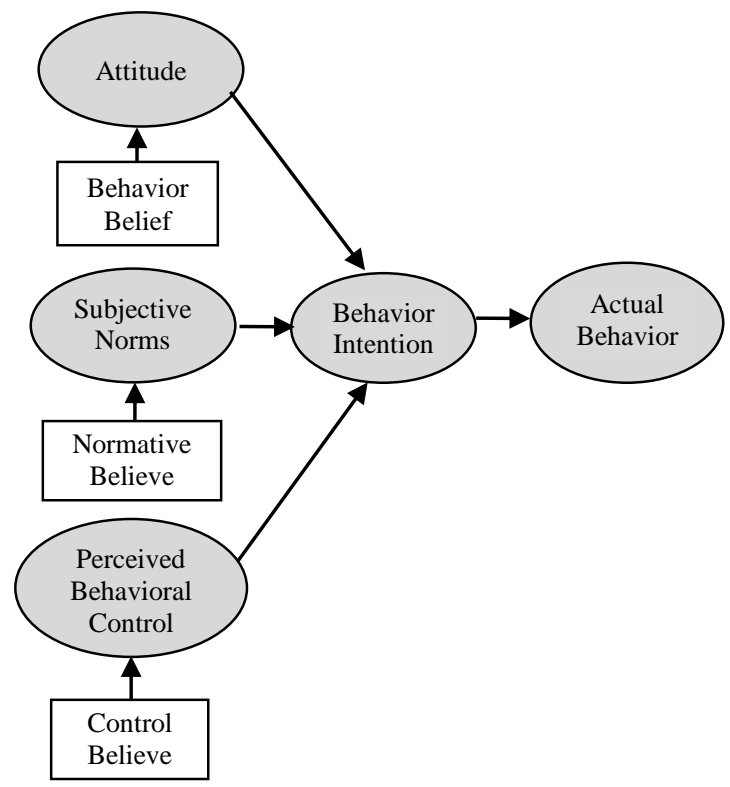

Figure 1. Theory of planned behavior $[1,2]$

Briefly, ATT refers to the degree to which a person has a favorable or unfavorable evaluation or appraisal of the behavior in question $[1,26,62]$, which can be traced back to an individual's behavioral beliefs. Behavioral belief reflects an individual expectation and evaluations of the outcomes of the behavior [2]. SN presents a social factor in the theory, which refers to the degree of perceived social pressure to perform or not to perform a certain behavior (e.g., the person's perception that others who are important to him/her and society think that he/she should (or not) perform the behavioral in question) [26:302]. Finally, PBC captures the extent to which a person has control over engaging in the behavior, and refers to the perceived ease or difficulty of completing or performing the behavior (e.g., the person's perception that he/she possesses the necessary skills, resources or opportunities to successfully perform the behavior) [1,2]. According to the theory, $\mathrm{PBC}$ is determined by control beliefs, which is about the presence of factors that may facilitate or impede the performance of the behavior [2]. As a general rule, when a person has positive attitudes and perceives positive opinions from others with greater self-ability of completing the behavior, the person is more disposed to perform a certain behavior.

Researchers should have reasonable validations behind their selection of a specific theory [32], mainly through rigorous justifications of why and how the selected theory fits in the context in which it is applied, and how it would be tied to the specific needs and aims of the research [31]. This is especially relevant in e-Participation context, where the majority of research works are widely criticized due to the lack of clear explanations of how the used theories were selected $[23,35,55]$. Hence, TPB is considered a steering theoretical framework for the current study for the following reasons:

1) TPB capacity to explain acceptance. TPB has been used and validated as a well-researched model for various topics in several contexts. For instance, citizen acceptance of e-Government services [47] and of mobile government services [33], and social media continuous usage $[5,15]$. Such studies have proved that user acceptance (represented by intention to use) can be appropriately explained by TPB. In eParticipation context, intention to use was found as a good predictor of citizens' decision to use ePetition [19] and e-Voting systems [68].

2) Voluntary behavior. TPB supposes that ATT, $\mathrm{SN}$, and $\mathrm{PBC}$ are more predictable of $\mathrm{BI}$ when the behavior in question is under person's voluntary control [2]. DeLone and McLean agree and support that the intention to use may be a more acceptable variable in the context of voluntary usage [22]. As we mentioned earlier, the nature of e-Participation context meets this requirement quite well, since e-Participation, through social media in particular, is a full voluntary action for citizens who can decide to participate or not $[17,19,24,36,55]$.

3) TPB extension and integration flexibility. The theory provides an effective and flexible conceptual framework to be complemented by external constructs to serve specific contexts $[1,2,16,62]$. The salient belief constructs of TPB 
(behavioral and normative beliefs) allow researchers to uncover more external factors that might impact that intention [2,7,62]. Hence, it is open to be supplemented/evolved by other factors to provide better explanatory power $[1,62]$, without the fear of losing the theoretical plausibility of the theory model $[33,47]$.

4) Returning to the theoretical roots of technology acceptance models. The extensive use of Technology Acceptance Model (TAM) [21] and the Unified Theory of Acceptance and Use of Technology (UTAUT) [64] - for example, in e-Government studies [31,52] - have diverted more researchers efforts away from investigating other important research factors related to user acceptance [8,31]. Some researchers call for returning to the theoretical roots of those models and using for instance TPB instead of TAM [8].

\section{Model development}

Overall, TPB has been found to be a useful theory for predicting behavior intentions [7,21,62,64]. However, it has some limited predictive ability as it explains $39 \%$ and $27 \%$ of the variation in $\mathrm{BI}$ and in $\mathrm{AB}$ constructs, respectively [7]. Many researchers have responded to such criticism by incorporating additional variables to the basic model of the theory, in an effort to produce more satisfactory explanations, likewise to fulfill and serve their research needs (see for example $[5,16,33]$ ). A pioneer attempt has been proposed in 1995 by Taylor and Todd [62]. These authors extended the main constructs of the theory (ATT, SN, and PBC) by decomposing them into indirect measures. Their model proposed that perceived usefulness (PU), perceived ease of use (PEOU), and compatibility (COMP) comprise ATT; peer influence and superior influence comprise $\mathrm{SN}$; and self-efficacy (SE) and facilitating conditions (FC) comprise PBC. Accordingly, better explanatory power has been reached; $55.36 \%$ of the variation in $\mathrm{BI}$ and $39.80 \%$ of the variation in $\mathrm{AB}$.

To predict citizens' intentions towards involvement in e-Participation through social media initiatives, it is reasonable to consider several factors associated with citizens' active participation. We consider such factors based on the literature review discussed in Section 3.

Accordingly, the proposed model, shown in Figure 2, postulates on the basis of the TPB main constructs (ATT, SN, and PBC), and extended first with one major construct, namely Perceived Value of citizen's involvement (PV). Second, we identify two relevant categories that precede and influence ATT and PV constructs; (1) characteristics of social media networks (CSM) as a platform for conducting eParticipation activities (includes PEOU, PU, COMP, and attractiveness (ATTRAC)); and (2) citizen trust (CT) - categorized as citizen trust in government and citizen trust in social media. Third, two main internal categories that comprise PBC construct; participation efficacy (PE) and $\mathrm{FC}$ - includes freedom to participate, and citizens' confidence in government ability and commitment to operate such initiatives. Table 1 shows the constructs and factors used in the proposed model including their origin and reference from literature.

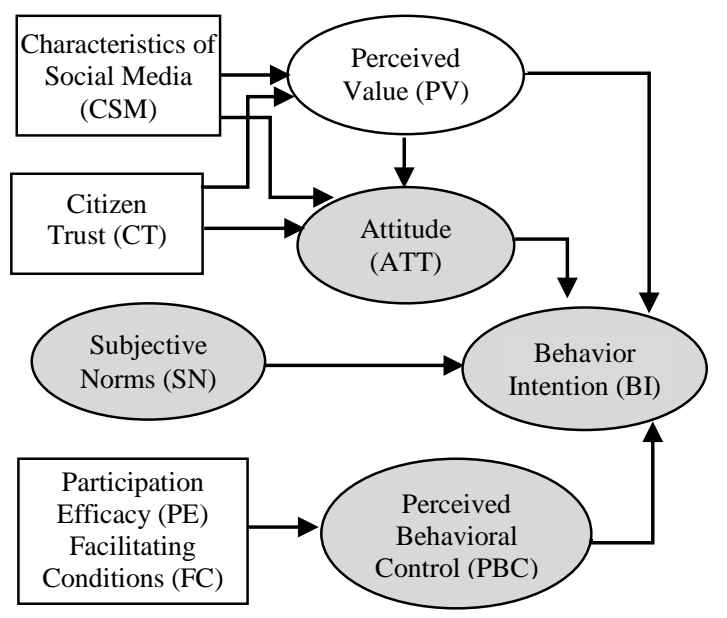

Figure 2. The proposed model

Table 1. Proposed Model - Constructs and Factors

\begin{tabular}{l|l|l|l}
\hline ID & DESCRIPTION & ORIGIN & REFERENCES \\
\hline ATT & $\begin{array}{l}\text { Attitude towards Act } \\
\text { or Behaviour }\end{array}$ & TPB & {$[1,26,62]$} \\
\hline BI & $\begin{array}{l}\text { Behaviour intention } \\
\text { (intention to use) }\end{array}$ & TPB & {$[1,62]$} \\
\hline CSM & $\begin{array}{l}\text { Characteristics of } \\
\text { social media }\end{array}$ & $\begin{array}{l}\text { Extended } \\
\text { construct }\end{array}$ & {$[34,49,51]$} \\
\hline CT & $\begin{array}{l}\text { Trust in Government } \\
\text { and in Technology }\end{array}$ & $\begin{array}{l}\text { Extended } \\
\text { construct }\end{array}$ & {$[13,31,47,63]$} \\
\hline FC & Facilitating Condition & $\begin{array}{l}\text { Extended } \\
\text { Factor }\end{array}$ & {$[62]$} \\
\hline PBC & $\begin{array}{l}\text { Perceived Behavioural } \\
\text { Control }\end{array}$ & TPB & {$[1,62]$} \\
\hline PE & Participation Efficacy & $\begin{array}{l}\text { Extended } \\
\text { Factor }\end{array}$ & {$[12]$} \\
\hline PV & Perceived Value & $\begin{array}{l}\text { Extended } \\
\text { Factor }\end{array}$ & {$[6,50,67]$} \\
\hline SN & Subjective Norms & TPB & {$[1,26,62]$} \\
\hline
\end{tabular}

In the next sections we examine the theoretical basis of the proposed model constructs; in particular,

${ }^{1}$ The construct reflects the features of social media networks as a mean, platform, or IS artefact [23] that might foster citizen to involve in e-Participation activities and to interact with government. Such technological characteristics or features are: PEOU, PU, COMP, and ATTRACT, which derived from $[21,54,62]$. 
the TPB original constructs (Section 5.1); and the new proposed construct and internal factors validity are discussed based on related work (Section 5.2).

\subsection{Theory of Planned Behavior constructs}

The three basic constructs of TPB include ATT, SB and PBC. While TPB suppose that ATT has a significant influence on BI, and $\mathrm{BI}$ is a good predictor of $\mathrm{AB}$, it also stresses that a behavior is not simply determined by personal ATT, but also by SN influences [1,68]. In meaning, BI of a person is influenced by opinions of others who are important to him/her, such as family and friends. Several prior studies in government context have widely proven the impact of ATT and SN on BI $[33,47]$. In the eParticipation context, citizens expect to interact with each other as well as with government. Such interactions conducted through social media would be publicly noticed by friends or relatives possessing social media accounts. Therefore, we argue that citizens tend to involve in e-Participation activities as a result of their personal attitude and through induction by others who are within their circle of influence. In thus, ATT and SN appear as crucial constructs when citizens decide to be involved in e-Participation.

PBC construct has received considerable empirical support as a significant predictor of BI $[1,62]$. PBC has been found as the second largest direct effect on citizens' intentions to use e-Government services [47]. The construct also appears to be an important factor of user intention to join social network sites [46], as well as to continue using them [5].

More recent theory improvements [2,68] advance that a person would intend to further engage in a behavior when he/she has more confidence in his/her SE, and when FC are available and supporting him/her to complete the behavior. Taken together, SE and FC, for example, explain $66 \%$ of the variance of PBC that in turn impact citizens intention to use mobile e-Government services [33].

\subsection{Complementary constructs and factors}

The proposed model extends TPB with the following constructs: PV, CSM, and CT as antecedents of ATT; and PE and FC as antecedent of PBC. The rationality for including them is explained in the following four sections.

5.2.1. Perceived value. Through e-Participation initiatives, citizens need to perceive that their participation involvement is taken seriously, that someone will be affected or that their contribution matters $[9,40,44,70]$. Usually, citizens will not participate if, for instance, a government does not listen to citizens and/or if they do not perceive an effect for their involvement in government affairs and decisions [40,60]. Generally, the literature review shows that such factor is not extensively researched in e-Participation studies. In accordance with TPB that an individual is likely to perform a behavior when that behavior is expected to produce a desirable outcome [2], as well as harmonizing with UTAUT model [64], which suggest that outcome expectations directly influence usage behavior, the current study stresses that citizens' expectations of producing a positive outcomes or value is significant to increase their tendency to get involved in e-Participation. In consequence, we extend TPB by adding a new major construct labeled "perceived value" (PV). Basically taken from a marketing concept, PV refers to "the consumer's overall assessment of the utility of a product based on what is received and what is given" [70:14]. PV is widely recognized as important factor to predict customers' behavioral intentions [18]. While such term is primary important in business organizations, non-profit organizations are not an exception [18]. In addition, [67] discusses about the important role of perceived value in citizens' continuance use of mobile government. Recently, the perceived value to citizens is one of major success factors that should be considered when designing eParticipation initiatives [50]. So, it deemed reasonable to suggest that positive citizens' expectations of values and benefits that they would perceive from engaging in e-Participation initiatives could increase their intention to involve in such initiatives. Examples of citizens' positive expectations of values and benefits include offering flexibility for citizens to provide feedback, ensuring government responsiveness, generating a culture of transparency and accountability, and improving the consideration of citizens' inputs in government decision-making processes. Additionally, we also argue that a positive ATT, that in turn creates more BI toward involving in e-Participation initiatives, may be a consequence of the citizens' evaluations of their believes about positive value of their contributions.

5.2.2. Characteristics of social media. With the aim of explaining and predicting Information Systems and Technology (IST) user's acceptance, Taylor and Todd indicate the importance of adding suitable factors to improve the applicability of TPB [62]. As we mentioned earlier, the authors indicated PU, PEOU, and COMP that comprise ATT. PEOU refers to "the degree to which a person believes that using a particular system would be free of effort", and PU is 
"the degree to which a person believes that using a particular system would enhance his/her job performance" [21:320]. Generally, citizens' intention to use a particular system will increase if they find that the system is useful (PU) and easy to use (PEOU) [21]. There is quite consensus among scholars about the significant impact of such two factors on citizens' acceptance and adoption of eGovernment systems [31,52].

Considering that interacting with government through social media is a significant change compared to interacting through official government websites, it can be assumed that citizens would be not involved unless they perceive that having such interaction is compatible or aligned with their individual lifestyles or values. Such assumption leads us to another potential factor - i.e. compatibility (COMP). The term refers to the degree in which an innovation (new technology) is perceived as being consistent with existing values and needs of potential adopters [54,62]. COMP has a direct impact in a person's attitude [62] and an impact on citizens' intention to use e-Government services [13]. The COMP factor highlights the significant importance of the context and seems respectively close to the term of "e-Participation tool relevance and appearance", suggested by Macintosh and Whyte in 2008 [36]. These authors describe such features as the degree to which an e-Participation tool is being liked enough to be used by intended users. Since citizens may feel more comfortable expressing themselves in social media context when opportunities arise [69], thus COMP may influence citizens' attitude. The attractiveness of e-Participation tool might also encourage citizens to get engaged [38, 54,56], which is also an emotional factor to supplement TPB as advised by [8]. Therefore, the current study suggests that social media characteristics - PEOU, PU, COMP, and ATTRACT - are expected to positively influence citizens' attitude towards their engagement in e-Participation initiatives.

Macintosh and Whyte [36] developed an analytical framework in order to evaluate the effectiveness of e-Participation initiatives in terms of engaging wider audience and influence the policy process. The authors proposed several evaluation criteria's that takes into account three perspectives: democratic, project and socio-technical. The later perspective considers to what extent the design of the digital tool used directly affects the outcomes. This research work also emphasizes that the role of eParticipation tool design might directly affect the eParticipation expected outcomes [36]. TAM and Delone and McLean models previously confirm that the overall technical performance of the system (such as PEOU) have a direct influence to the perceived value of using that system [21,22]. Therefore, the current study suggests also that social media characteristics - PEOU, PU, COMP, and ATTRACT - are expected to positively influence citizens' perceived value of engaging in e-Participation through social media. Such values include, for example, easily enabling citizens to connect with government officials; providing citizens with updated and valued information; and facilitating their contributions to policy and government decisionmaking processes.

5.2.3. Citizens trust. It is extensively supported that citizens' trust in government plays a significant role as a motivator for citizens' acceptance and adoption of e-Government systems [31]. However, the concept of trust is not far researched in the context of e-Participation [58]. This research adapts the definition of "trust in government" to the e-Participation context, considering it as the extent to which citizens believe that government is reliable and can be trusted in carrying out e-Participation transactions [13]. Several studies emphasized that citizens must not only trust in government but also in the technologies they use to perform the online transactions [13,31]. As social media networks are provided by third-party entities, trust in social media, which described as citizens' positive or negative feeling about performing various target behavioral actions on social media [59], might impact citizens ATT and PV. In sum, the higher the citizens' trust in government is, as well as the higher their trust in social media is, the more positive will be the ATT and $\mathrm{PV}$, and consequently citizens' intention towards involvement will be higher.

\subsubsection{Participation efficacy, Facilitating} conditions. For specific interest concerning PBC construct, an important addition to such construct is related to the recognition of two dimensions, namely $\mathrm{PE}$ and FC. The first dimension reflects a citizen belief about his/her capability to participate [27]. The term is derived from the political efficacy concept, which is defined as a citizen feeling of his/her ability to play an important part in making political and social changes possible [12:187]. The sense of political efficacy is considered a predictor factor for citizens' political engagement [28,29]. More recently, participation efficacy has introduced and confirmed as a significant predictor of intention to participate in government-led e-Participation initiatives [4]. PE is proposed for the purpose of this research as responding to calls for capturing suitable factors that enhance the applications of e-Participation [35], and 
also to capture emotional factors that were excluded in the original TPB model [8]. Consequently, it can be assumed that if a person is confident in his/her ability to participate, then he/she would be likely to involve in e-Participation activities. Few prior studies have discussed or attempt to conceptualize the participation efficacy term [4], which we define it here as a citizen's belief in his/her ability and capability to participate in e-Participation initiatives. The present study suggests that a strong sense of participation efficacy can heighten an intention to get citizens involved in e-Participation initiatives.

The FC category refers to the objective factors in the environment that make an act of use easy to accomplish [2]. Here, we notice that many of the eParticipation initiatives presenting low level of citizens engagement were being operated under the absence of real commitment for adopting truly dialogue with citizens [9,65]. In addition, [25,39] have also questioned government's ability to manage e-Participation initiatives. By analyzing data from 500 U.S cities, the studies shown that using social media forums to interact with citizens certainly require more efforts from government institutions than those that rely on traditional methods, e.g. sending e-mails [25]. Therefore, it is reasonable to consider that the general positive atmosphere of freedom for citizens to participate and theirs' believes in government commitment and ability to manage such e-Participation initiatives appear as significant key factors for attracting more citizens which in turn create more positive attention towards involvement in e-Participation through social media initiatives.

In sum, we consider PE and FC important factors that are expected to jointly influence PBC.

Based on our analysis, we argue that the hypotheses of the proposed model are supported by related work. The relationships and the corresponding references are depicted in Table 2.

Table 2. Hypotheses and Supporting Studies

\begin{tabular}{l|l}
\hline RELATIONSHIP $($ OR & SUPPORTING STUDIES \\
HYPOTHESES $)$ & \\
\hline $\mathrm{AT} \rightarrow \mathrm{BI}$ & {$[5,21,33,46,47,53]$} \\
\hline $\mathrm{PV} \rightarrow \mathrm{BI}$ & {$[36,50,55,64]$} \\
\hline $\mathrm{SN} \rightarrow \mathrm{BI}$ & {$[5,33,46,53]$} \\
\hline $\mathrm{PBC} \rightarrow \mathrm{BI}$ & {$[5,33,46,47,53,62]$} \\
\hline $\mathrm{PV} \rightarrow \mathrm{ATT}$ & {$[6]$} \\
\hline $\mathrm{CSM} \rightarrow \mathrm{ATT}$ includes & \\
$\bullet \mathrm{PU} \rightarrow \mathrm{ATT}$ & {$[6,33]$} \\
$\bullet \mathrm{PEOU} \rightarrow \mathrm{ATT}$ & {$[6,13,21,62]$} \\
$\bullet \mathrm{COMP} \rightarrow \mathrm{ATT}$ & {$[8,54,62]$} \\
$\bullet \mathrm{ATTRACT} \rightarrow \mathrm{ATT}$ & {$[34,49,51]$} \\
\hline $\mathrm{CSM} \rightarrow \mathrm{PV}$ & Derived from $[21,22,36]$ \\
\hline $\mathrm{CT} \rightarrow \mathrm{PV}$ & {$[6]$} \\
\hline $\mathrm{CT} \rightarrow \mathrm{ATT}$ & {$[6,13,46,47,58,63]$} \\
\hline $\mathrm{FC} \rightarrow \mathrm{PBC}$ & {$[33,53]$} \\
\hline $\mathrm{PE} \rightarrow \mathrm{PBC}$ & {$[4,28]$} \\
\hline
\end{tabular}

\section{Conclusion and future work}

Given the expanding use of social media for government e-Participation initiatives, there is a need to better understand citizen's perception towards engaging in such initiatives. Currently, citizen acceptance and adoption factors is a scant topic in e-Participation research.

Since e-Participation is a complex and human intensive activity, where various factors are expected to affect citizen's participation, we considered TPB as an adequate theory to ground our study and expanded it to be applied to the e-Participation context. The extended model focuses on factors determining usage intention. It explains and predicts citizens' intention to be involved in e-Participation through social media. It also represents a starting point for understanding the e-Participation through social media phenomenon from the point of view of the citizens.

Our aim was to identify relevant factors that can influence citizens' intentions to involve in eParticipation through social media initiatives. The factors were delineated based on a review of established research from psychology, eGovernment, e-Participation, Political Science, IS and Information Technology. The proposed model consists of the main constructs of TPB (ATT, SN, and PBC), extended by several constructs: PV, CSM, $\mathrm{CT}, \mathrm{PE}$, and FC. In summary, the constructs added to the TPB are those considered relevant for influencing citizens' intention to accept and engage in government-led e-Participation through social media initiatives.

Currently, we are developing research instruments to collect data that will allow us to conduct the empirical validation of the proposed model. This validation is the main focus of our future work.

\section{References}

[1] Ajzen, I. The theory of planned behavior. Organizational behavior and human decision processes 50, 2 (1991), 179-211.

[2] Ajzen, I. Constructing a theory of planned behavior questionnaire. Unpublished manuscript, (2006).

[3] Alarabiat, A. and Soares, D. Electronic Participation Through Social Media. Proceedings of the 9th International Conference on Theory and Practice of Electronic Governance, ACM (2016), 191-194.

[4] Alathur, S., Ilavarasan, P., and Gupta, M. Determinants of e-participation in the citizens and the government initiatives: Insights from India. Socio-Economic Planning Sciences 55, (2016), 25-35.

[5] Al-Debei, M., Al-Lozi, E., and Papazafeiropoulou, A. Why people keep coming back to Facebook: Explaining and predicting continuance participation from an extended 
theory of planned behaviour perspective. Decision support systems 55, 1 (2013), 43-54.

[6] Al-Hujran, O., Al-Debei, M., Chatfield, A., and Migdadi, M. The imperative of influencing citizen attitude toward e-government adoption and use. Computers in Human Behavior 53, (2015), 189-203.

[7] Armitage, C. and Conner, M. Efficacy of the theory of planned behaviour: A meta-analytic review. British journal of social psychology 40, 4 (2001), 471-499.

[8] Benbasat, I. and Barki, H. Quo vadis TAM? Journal of the association for information systems 8, 4 (2007), 7.

[9] Bertot, J., Jaeger, P., and Grimes, J. Using ICTs to create a culture of transparency: E-government and social media as openness and anti-corruption tools for societies. Government Information Quarterly 27, 3 (2010), 264-271. [10] Bonsón, E., Royo, S., and Ratkai, M. Citizens' engagement on local governments' facebook sites. an empirical analysis: The impact of different media and content types in western europe. Government Information Quarterly 32, 1 (2015), 52-62.

[11] Brown, S., Venkatesh, V., Kuruzovich, J., and Massey, A. Expectation confirmation: An examination of three competing models. Organizational Behavior and Human Decision Processes 105, 1 (2008), 52-66.

[12] Campbell, A., Gurin, G., and Miller, W. The voter decides. (1954).

[13] Carter, L. and Bélanger, F. The utilization of egovernment services: citizen trust, innovation and acceptance factors*. Information Systems Journal 15, 1 (2005), 5-25.

[14] Charalabidis, Y., Loukis, E., Androutsopoulou, A., Karkaletsis, V., and Triantafillou, A. Passive crowdsourcing in government using social media. Transforming Government: People, Process and Policy 8, 2 (2014), 283-308.

[15] Chen, S.-C., Yen, D., and Hwang, M. Factors influencing the continuance intention to the usage of Web 2.0: An empirical study. Computers in Human Behavior 28, 3 (2012), 933-941.

[16] Chu, P.-Y., Hsiao, N., Lee, F.-W., and Chen, C.-W. Exploring success factors for Taiwan's government electronic tendering system: behavioral perspectives from end users. Government Information Quarterly 21, 2 (2004), 219-234.

[17] Coleman, R., Lieber, P., Mendelson, A., and Kurpius, D. Public life and the internet: if you build a better website, will citizens become engaged? New Media \& Society 10, 2 (2008), 179-201.

[18] Cronin, J., Brady, M., and Hult, G. Assessing the effects of quality, value, and customer satisfaction on consumer behavioral intentions in service environments. Journal of retailing 76, 2 (2000), 193-218.

[19] Cruickshank, P. and Smith, C. Understanding the "ePetitioner." Transforming Government: People, Process and Policy 5, 4 (2011), 319-329.

[20] Cruickshank, P. and Smith, C. Self-efficacy as a factor in the evaluation of epetitions. Proceedings of EDEM, (2009), 223-232.

[21] Davis, F. Perceived usefulness, perceived ease of use, and user acceptance of information technology. MIS quarterly, (1989), 319-340.
[22] Delone, W. and McLean, E. The DeLone and McLean model of information systems success: a ten-year update. Journal of management information systems 19, 4 (2003), 9-30.

[23] Dini, A. and Øystein, S. The Current State of Social Media Research for eParticipation in Developing Countries: A Literature Review. IEEE (2016), 2698-2707.

[24] Edelmann, N. and Cruickshank, P. Introducing psychological factors into e-participation research. $E$ governance and Civic Engagement: Factors and Determinants of E-Democracy, (2012), 338-361.

[25] Feeney, M. and Welch, E. Electronic participation technologies and perceived outcomes for local government managers. Public Management Review 14, 6 (2012), 815833.

[26] Fishbein, M. and Ajzen, I. Belief, attitudes, intention, and behavior. An introduction to theory and research. Massachussets: Addison-Wesley, (1975).

[27] Freschi, A., Medaglia, R., and Jacob, N. eParticipation in the institutional domain: a review of research. Analytical report on eParticipation research from an administration and political perspective in six European countries. (2009).

[28] Gastil, J. and Xenos, M. Of attitudes and engagement: Clarifying the reciprocal relationship between civic attitudes and political participation. Journal of Communication 60, 2 (2010), 318-343.

[29] Gil de Zúñiga, H., Molyneux, L., and Zheng, P. Social media, political expression, and political participation: Panel analysis of lagged and concurrent relationships. Journal of Communication 64, 4 (2014), 612-634.

[30] Hofmann, S., Beverungen, D., Räckers, M., and Becker, J. What makes local governments' online communications successful? Insights from a multi-method analysis of Facebook. Government Information Quarterly 30, 4 (2013), 387-396.

[31] Hofmann, S., Räckers, M., and Becker, J. Identifying factors of e-government acceptance-a literature review. (2012).

[32] Hong, S.-J. and Tam, K. Understanding the adoption of multipurpose information appliances: The case of mobile data services. Information systems research 17, 2 (2006), 162-179.

[33] Hung, S.-Y., Chang, C.-M., and Kuo, S.-R. User acceptance of mobile e-government services: An empirical study. Government Information Quarterly 30, 1 (2013), 3344.

[34] Lacigova, O., Maizite, A., and Cave, B. eParticipation and social media: A symbiotic relationship. European Journal of ePractice 16, (2012), 71-76.

[35] Macintosh, A., Coleman, S., and Schneeberger, A. eParticipation: The research gaps. Lecture Notes in Computer Science (including subseries Lecture Notes in Artificial Intelligence and Lecture Notes in Bioinformatics) 5694 LNCS, (2009), 1-11.

[36] Macintosh, A. and Whyte, A. Towards an evaluation framework for eParticipation. Transforming Government: People, Process and Policy 2, 1 (2008), 16-30.

[37] Medaglia, R. eParticipation research: Moving characterization forward (2006-2011). Government Information Quarterly 29, 3 (2012), 346-360. 
[38] Mergel, I. A framework for interpreting social media interactions in the public sector. Government Information Quarterly 30, 4 (2013), 327-334.

[39] Mergel, I. Social media adoption and resulting tactics in the US federal government. Government Information Quarterly 30, 2 (2013), 123-130.

[40] Mkude, C. and Wimmer, M. Studying Interdependencies of E-government Challenges in Tanzania along a Pestel Analysis. (2015).

[41] Mossberger, K., Wu, Y., and Crawford, J. Connecting citizens and local governments? Social media and interactivity in major US cities. Government Information Quarterly 30, 4 (2013), 351-358.

[42] Mustafa Kamal, M. An analysis of e-Participation research: moving from theoretical to pragmatic viewpoint. Transforming Government: People, Process and Policy 3, 4 (2009), 340-354.

[43] OECD. Participative web and User-created Content: Web 2.0, wikis and social networking. The Organisation for Economic Co-operation and Development (OECD), Paris, 2007.

[44] OECD. Focus on citizens: public engagement for better policy and services. Organisation for Economic Cooperation and Development, 2009.

[45] Oliveira, G. and Welch, E. Social media use in local government: Linkage of technology, task, and organizational context. Government Information Quarterly 30, 4 (2013), 397-405.

[46] Osorio, C. and Papagiannidis, S. Main Factors for Joining New Social Networking Sites. In HCI in Business. Springer, 2014, 221-232.

[47] Ozkan, S. and Kanat, I. e-Government adoption model based on theory of planned behavior: Empirical validation. Government Information Quarterly 28, 4 (2011), 503-513.

[48] Panagiotopoulos, P., Sams, S., Elliman, T., and Fitzgerald, G. Do social networking groups support online petitions? Transforming Government: People, Process and Policy 5, 1 (2011), 20-31.

[49] Panopoulou, E., Tambouris, E., and Tarabanis, K. eParticipation initiatives in Europe: learning from practitioners. In Electronic Participation. Springer, 2010, 54-65.

[50] Panopoulou, E., Tambouris, E., and Tarabanis, K. Success factors in designing eParticipation initiatives. Information and Organization 24, 4 (2014), 195-213.

[51] Prieto-Martín, P., de Marcos, L., and Martínez, J. A Critical Analysis of EU-Funded eParticipation. In Y. Charalabidis and S. Koussouris, eds., Empowering Open and Collaborative Governance. Springer Berlin Heidelberg, 2012, 241-262.

[52] Rana, N., Dwivedi, Y., and Williams, M. Evaluating alternative theoretical models for examining citizen centric adoption of e-government. Transforming Government: People, Process and Policy 7, 1 (2013), 27-49.

[53] Rana, N., Williams, M., Dwivedi, Y., and Williams, J. Theories and theoretical models for examining the adoption of e-government services. E-service Journal 8, 2 (2012), 26-56.

[54] Rogers, M. Diffusion of innovations. New York, (1995).
[55] Sæbø, Ø., Rose, J., and Flak, L. The shape of eParticipation: Characterizing an emerging research area. Government information quarterly 25, 3 (2008), 400-428.

[56] Sæbø, Ø., Rose, J., and Nyvang, T. The Role of Social Networking Services in eParticipation. In A. Macintosh and E. Tambouris, eds., Electronic Participation. Springer Berlin Heidelberg, 2009, 46-55.

[57] Sanchez-Nielsen, E. and Lee, D. eParticipation in Practice in Europe: The Case of " Puzzled by Policy: Helping You Be Part of EU.” IEEE (2013), 1870-1879.

[58] Scherer, S. and Wimmer, M. Conceptualising Trust in E-Participation Contexts. In E. Tambouris, A. Macintosh and F. Bannister, eds., Electronic Participation. Springer Berlin Heidelberg, 2014, 64-77.

[59] Shin, D.-H. The effects of trust, security and privacy in social networking: A security-based approach to understand the pattern of adoption. Interacting with computers 22,5 (2010), 428-438.

[60] Susha, I. and Grönlund, A. eParticipation research: Systematizing the field. Government Information Quarterly 29, 3 (2012), 373-382.

[61] Susha, I. and Grönlund, T. Context clues for the stall of the Citizens' Initiative: Lessons for opening up eparticipation development practice. Government Information Quarterly 31, 3 (2014), 454-465.

[62] Taylor, S. and Todd, P. Decomposition and crossover effects in the theory of planned behavior: A study of consumer adoption intentions. International journal of research in marketing 12, 2 (1995), 137-155.

[63] Titah, R. and Barki, H. E-government adoption and acceptance: A literature review. International Journal of Electronic Government Research (IJEGR) 2, 3 (2006), 2357.

[64] Venkatesh, V., Morris, M., Davis, G., and Davis, F. User acceptance of information technology: Toward a unified view. MIS quarterly, (2003), 425-478.

[65] Wahid, F. and Sæb $\varnothing, \varnothing$. Understanding eParticipation services in indonesian local government. Lecture Notes in Computer Science (including subseries Lecture Notes in Artificial Intelligence and Lecture Notes in Bioinformatics) 8407 LNCS, (2014), 328-337.

[66] Wahid, F. and Sæbø, Ø. Affordances and Effects of Promoting eParticipation Through Social Media. In E. Tambouris, P. Panagiotopoulos, Ø. Sæbø, et al., eds., Electronic Participation. Springer International Publishing, 2015, 3-14.

[67] Wang, C. Antecedents and consequences of perceived value in Mobile Government continuance use: An empirical research in China. Computers in Human Behavior 34, (2014), 140-147.

[68] Yao, Y. and Murphy, L. Remote electronic voting systems: an exploration of voters' perceptions and intention to use. European Journal of Information Systems 16, 2 (2007), 106-120.

[69] Yu, R. The relationship between passive and active non-political social media use and political expression on Facebook and Twitter. Computers in Human Behavior 58, (2016), 413-420.

[70] Zeithaml, V. Consumer perceptions of price, quality, and value: a means-end model and synthesis of evidence. The Journal of marketing, (1988), 2-22. 